\title{
BMJ Open Determinants of acceptance of patients with heart failure and their informal caregivers regarding an interactive decision-making system: a qualitative study
}

To cite: Zippel-Schultz B, Palant A, Eurlings C, et al. Determinants of acceptance of patients with heart failure and their informal caregivers regarding an interactive decision-making system: a qualitative study. BMJ Open 2021;11:e046160. doi:10.1136/ bmjopen-2020-046160

- Prepublication history and supplemental material for this paper is available online. To view these files, please visit the journal online (http://dx.doi. org/10.1136/bmjopen-2020046160).

BZ-S, AP and CE are joint first authors.

Received 21 October 2020 Accepted 10 May 2021

Check for updates

(C) Author(s) (or their employer(s)) 2021. Re-use permitted under CC BY-NC. No commercial re-use. See rights and permissions. Published by BMJ.

For numbered affiliations see end of article.

Correspondence to Dr Alexander Palant; palant@dsck.de

\section{ABSTRACT}

Objective Heart failure is a growing challenge to healthcare systems worldwide. Technological solutions have the potential to improve the health of patients and help to reduce costs. Acceptability is a prerequisite for the use and a successful implementation of new disruptive technologies. This qualitative study aimed to explore determinants that influence the acceptance of patients and their informal caregivers regarding a patient-oriented digital decision-making solution-a doctor-at-home system.

Design We applied a semistructured design using an interview guide that was based on a theoretical framework influenced by established acceptance theories. The interviews were analysed using a content analysis. Setting A multicentred study in four European countries. Participants We interviewed 49 patients and 33 of their informal caregivers. Most of the patients were male (76\%) and aged between 60 and 69 years (43\%). Informal caregivers were mostly female (85\%). The majority of patients $(55 \%)$ suffered from heart failure with mild symptoms.

Results Four main categories emerged from the data: needs and expectations, preferences regarding the care process, perceived risk and trust. Participants expressed clear wishes and expectations regarding a doctor-athome, especially the need for reassurance and support in the management of heart failure. They were receptive to changes to the current healthcare processes. However, trust was identified as an important basis for acceptance and use. Finally, perceived risk for decision-making errors is a crucial topic in need of attention.

Conclusion Patients and informal caregivers see clear benefits of digitalisation in healthcare. They perceive that an interactive decision-making system for patients could empower and enable effective self-care. Our results provide important insights for development processes of patient-centred decision-making systems by identifying facilitators and barriers for acceptance. Further research is
Strengths and limitations of this study

This is the first qualitative study to explore factors influencing patients and their informal caregivers' acceptance of an artificial intelligence supported interactive decision-making system for selfmanagement of heart failure.

- For a qualitative study a relatively large sample size was included for interviewing patients and informal caregivers.

- A multidisciplinary team of researchers from different European countries was involved in the development of the interview guide and the analysis of the results.

- Comprehensive content analysis and multiple triangulation were used to identify patients and informal caregivers' expectations and struggles regarding digital health.

- The study is limited by an imbalance in gender, racial and educational diversity.

needed, especially regarding the influence and mitigation of patients and informal caregivers' perceived risks.

\section{INTRODUCTION}

Heart failure (HF) is the fastest growing cardiovascular disease in terms of prevalence. ${ }^{12}$ It is one of the top five causes of adult death worldwide and the main cause of hospitalisations in those aged 65 years or older. ${ }^{1}$ Recurring emergency room visits, hospital readmissions and longer stays place immense financial burden on healthcare services. ${ }^{3} 4$ These costs will continue to rise.

Patients with HF have an impaired quality of life that further declines after each 
rehospitalisation. ${ }^{5} \mathrm{~A}$ key challenge in the management of HF is the timely adjustment of the therapy according to the patients' needs to avoid a deterioration of the disease. This inertia of treatment adaptions will become more evident, ${ }^{67}$ not least because of an increasing unequal distribution of medical care in rural versus urban regions and an increasing gap between the growing number of patients with $\mathrm{HF}$ and available healthcare resources. ${ }^{8}$ Alternative healthcare approaches that provide accessible and personalised medical care are required. ${ }^{9}$

Effective self-management has the potential to improve the health of patients at reduced costs. ${ }^{10}$ Digital medicine (eg, telemedicine, artificial intelligence (AI)) shows much promise to actively support the required paradigm shift. ${ }^{11}$ Care processes integrating new technologies have been shown to improve patients' health through close monitoring and timely therapeutic adjustments, ${ }^{12}$ offer personalised approaches and/or increase knowledge and adherence. ${ }^{13-15}$

The project 'PASSION-HF' (PAtient Self-care uSing eHealth In chrONic Heart Failure, funded by the European Programme INTERREG-NWE 702) pursues to compensate for limited human resources, to reduce HF-related costs and simultaneously to improve the quality of healthcare. The objective is to develop an interactive decision-making system for patients-a doctorat-home - that provides evidence-based treatment advice directly to patients with HF and their informal caregivers, enabling effective self-management. ${ }^{16}$ The doctor-at-home will empower users with skills to manage their HF in an individual, more independent way with limited supervision by healthcare professionals.

Since patients and informal caregivers will be encouraged to integrate the doctor-at-home into their daily care routines, the way care is delivered will change fundamentally, thus acceptance is a prerequisite for its successful implementation. It is therefore important to include potential users as early as possible in the development of the product, helping the designers to gain a better understanding of their preferences and expectations and to ensure that development is tailored towards their specific needs. ${ }^{17}$ Therefore, the aim of the study was to explore determinants that may facilitate or hamper the acceptance of patients and informal caregivers regarding the use of the doctor-at-home.

\section{METHOD}

\section{Approach and context}

This qualitative study encompassed interviews with patients with $\mathrm{HF}$ and their informal caregivers. We employed a multiple triangulation design by combining different data sources and investigators. While data source triangulation might facilitate a better understanding of the study phenomenon, ${ }^{18}$ investigator triangulation decreases a potential bias in gathering information. ${ }^{19}$ The interviews had a semistructured design using two different interview guides for patients and informal caregivers. All documents were developed by multidisciplinary experts from four European countries: Germany, Ireland, the Netherlands and UK, representing cardiology, psychology, technology, sociology and innovation management. The theoretical framework for the interview guide was based on the Unified Theory of Acceptance and Use of Technology. ${ }^{20}$ Following this theory, the benefits that potential users expect from the doctor-at-home (performance expectation), and the expected change in behaviour (effort expectancy), critically influence the acceptance of and the adherence to a system. ${ }^{21-23}$ We enhanced the interview guide by additional aspects proven important within other research contexts, namely risk and trust. ${ }^{24}$ The first drafts of the documents were designed in German and English and critically revised by all members of the research team. The final version was translated by the Dutch team into Dutch.

\section{Sampling strategy and recruitment}

A maximum variation sampling approach was implemented for the recruitment to aim for a broad variety of patients with HF with key considerations of age, gender, social background and disease severity, determined by the New York Heart Association (NYHA) classification. ${ }^{25}$

Participants were recruited across the four countries, either during HF-related hospitalisation or a routine outpatient visit. Informal caregivers were mostly family members of these patients. Inclusion criteria were as follows: (1) $\geq 18$ years; (2) diagnosis of $\mathrm{HF}$ or caring for someone with HF; (3) cognitive receptivity; (4) conversant in the language of the interview; (5) willingness to participate; and (6) willingness for the interview to be recorded.

\section{Data collection}

After ethical approval at each clinical site, interviews took place between March and June 2019. The interview protocol was developed by AP (sociologist and experienced in interviewing) and critically revised by the coauthors. AP performed one-on-one training for all researchers conducting the interviews and closely monitored the interview process. Interviews lasted between 20 min and 1 hour. All participants were informed about the purpose and the format of the study. Written informed consent was obtained prior to commencement.

Most interviews with patients and their informal caregivers were conducted separately, unless a request was made to be interviewed together (three in total). In order to look at the phenomenon in a different setting, we additionally conducted a focus group with eight participants at the site of the project leader. At the beginning of the interviews and focus group, patients and caregivers were shown an online demonstration of another virtual coach for patients with $\mathrm{HF}$ as a first idea of how the future doctorat-home might look like. ${ }^{26}$ During the interviews and the focus group, each question was read out loud in the same order, except if the question had been answered before. During dyadic interviews of patients and their informal 
caregivers, the participants were asked to concentrate on their individual interview guide. We therefore treated the dyadic interviews as individual interviews. Field notes, which contained the researcher's first impressions of participant answers, were used to enrich data analysis. Interviews were performed either in the patient's home or at the hospital site, depending on participants' preferences.

\section{Data analysis}

Interviews were audiotaped and transcribed verbatim by a transcription office. Dutch interviews were translated into English and German by the Dutch investigators. Analysis of the interviews was performed using the 'ATLAS.ti' software and completed in August 2019. A content analysis according to Mayring ${ }^{27}$ was used with the aim to find overall connections in the data and to discover common patterns. ${ }^{28}$ The objective of this method is to systematically transform a large amount of text into a highly organised and concise summary of key results. The researcher uses the analysis of the raw data from verbatim transcribed interviews to form categories or themes in a process of further abstraction of data at each step of the analysis; from manifest and literal content to latent meanings.

The interviews were analysed and sorted into a coding scheme describing the meaning of the text. Similar codes were grouped into categories and subcategories (see online supplemental material) to identify the main themes by framing differentiated concepts. Individual interviews and the focus group were analysed separately. The focus group was dynamic and included a lively interactive exchange. The results of the focus group supported the results of the individual interviews and strengthened the findings. Therefore, they are not presented separately.

Preliminary results were discussed once a month during videoconferences with the interviewers. We intended to reduce possible biases during the process by discussing ambiguities and reaching a common consensus. Subsequently, we conducted expert interviews with cardiologists at each clinical site in order to verify the results of the analysis. The final results were achieved by consensus of all partners in November 2019. The following pronouns were used to give an impression for the response frequencies of the participants: some (approximately less than onethird), many (approximately between one-third and two-thirds) and most (approximately more than twothirds). Frequencies were calculated to evaluate the demographic data.

\section{Patient and public involvement}

Patients were not involved in the design or conduct of the study. The findings of this study have influenced the design of the doctor-at-home. Reporting, dissemination and discussion of findings will involve both patient and caregiver representatives.
RESULTS

We interviewed 49 patients and 33 informal caregivers. Most patients were male $(76 \%)$ and aged between 60 and 69 years $(43 \%)$. Informal caregivers were mostly female $(85 \%)$. Only $22 \%$ of the patients, yet $45 \%$ of informal caregivers were under 60 years old. Most patients (55\%) suffered from HF with mild symptoms (NYHA class II), $18 \%$ experienced marked and $2 \%$ had severe symptoms (table 1).

Four key themes emerged from the data: (1) needs and expectations, giving information about the expected benefits, (2) preferences, as a reflection of the necessary learning effort or the change in behaviour to be made, when using the system, (3) perceived risk, focusing on possible errors, and (4) trust, based on the belief that the doctor-at-home delivers what is promised. All corresponding quotes can be found in table 2 .

\section{Needs and expectations}

Patients and informal caregivers stated their needs and clear expectations emerging from their needs regarding their care processes. The most frequently expressed needs were their desire for reassurance and a wish for more support.

\section{Desire for reassurance}

Both patients and informal caregivers expressed a desire to feel safe and reassured regarding the patients' health. Most patients reported a frequent uncertainty about their health and the interpretation of symptoms. Therefore, many expected that a doctorat-home could give them advice on how to manage or interpret their symptoms and make them feel safer. Furthermore, our participants expressed expectations that a doctor-at-home could monitor the patients' health status. This could give both groups a sense of security, especially as most participants reported states of anxiety associated with the HF. Specifically, many expressed the desire that the envisioned background monitoring by the application should be active around the clock. This matched their wishes to receive help in situations where doctors were difficult or impossible to reach.

Some patients hoped that a doctor-at-home would be able to predict a decline in health. For patients, this seemed to be a logical outcome of constant monitoring. Many patients and informal caregivers found this preventive aspect most useful and reassuring.

Another mentioned aspect was the expectation of patients that a doctor-at-home should be able to identify side effects and interactions between drugs better than a doctor. They suggested that the system to be developed could warn patients and doctors about it.

\section{Wish for support}

The strong desire for reassurance was accompanied by a wish for more support. Many participants saw the envisioned doctor-at-home as a potential daily 
Table 1 Characteristics of patients and informal caregivers overall and per country

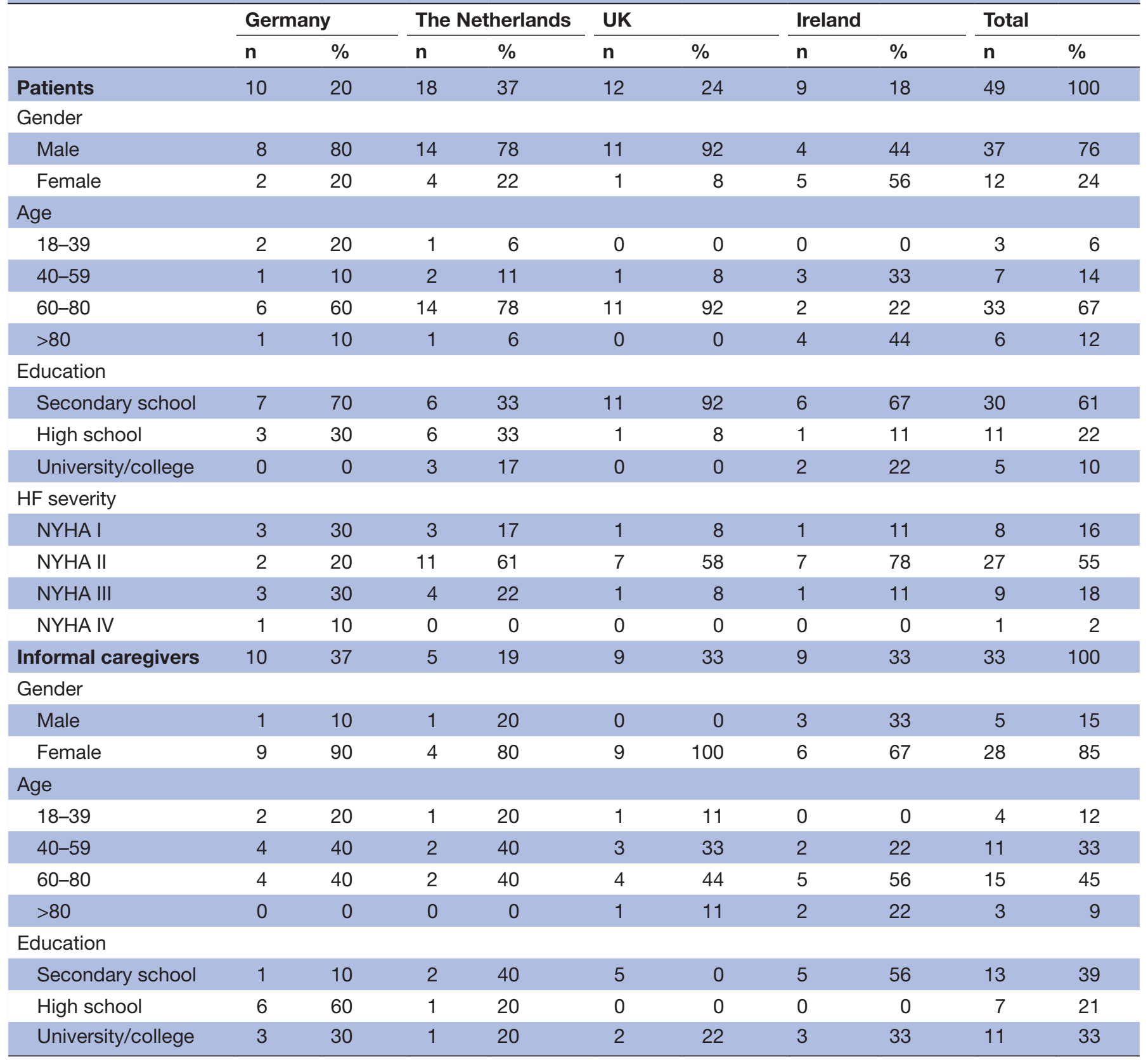

HF, heart failure; NYHA, New York Heart Association.

companion supporting management of their daily routines. A general consensus was expressed by both patients and informal caregivers that they did not want or dare to bother the doctor each time they had a question. Most patients and informal caregivers explicitly expressed their desire for easily accessible advice at all hours.

Besides, some patients reported that their doctors were often unable to provide them with satisfactory information, for example, about the necessary lifestyle changes. Some noted that suggestions from doctors or relevant brochures were often unhelpful for the individual patient. This lack of support led some patients feeling unsupported and isolated with the disease, and they hoped that the doctor-at-home could fill this void in the future. Regarding necessary lifestyle modification, many patients had expectations of recommendations that would be tailored to their individual health situation and physical capacity.

Many informal caregivers expected a support that addresses their tasks and fears concerning the management of the patients' disease and therefore a reliever to their burden. They described a feeling of powerlessness, and also wanted and needed more support and reassurance. 
Table 2 Themes and example quotes of the qualitative interviews

\begin{tabular}{ll} 
Theme & Example quotes \\
\hline $\begin{array}{l}\text { Needs and } \\
\text { expectations: } \\
\text { desire for }\end{array}$ & Patients \\
$\begin{array}{l}\text { reassurance } \\
\text { 'And if I feel worse then, she [the potential doctor-at-home] measures again. I feel monitored in principle or well looked after }\end{array}$
\end{tabular}

reassurance

'The fact you can get in touch right away, morning, noon or night [with the potential doctor-at-home]. With your doctor you have to make an appointment, or it might be Sunday and difficult to contact him, whereby the [envisioned] application, obviously, you press a button, which is very reassuring.' (Ireland, female, 70-79 years)

'Yes. Listen, doctors are expected to be able to handle all of these guidelines, prescriptions, and medications, etc. But it works faster on the computer, I think. If you program it correctly, it filters out a million possibilities in a minute, so to speak.' (The Netherlands, male, $70-79$ years)

'... that [the envisioned doctor-at-home] uses the technology to make you feel like I'm out there and when something happens there's somebody who's watching me, and alerting or calling for help. Then you have confidence, then you have reassurance. (The Netherlands, male, participant of focus group, 60-69 years)

\section{Informal caregivers}

'I do think, it'll be helpful for a lot of people, because the people l've spoken to here, are very frightened. They really don't understand, what's going on. (...) To know, that's okay. Your weight is up today, but it might be down tomorrow. (...) Instead of rushing to the ER [emergency room], because I think I'm breathless.' (Ireland, female, 70-79 years)

'I think he [the patient, husband of the interviewee] needs more support, (...), to take the fear away from him, really this fear that is always with him.' (Germany, female, 40-49 years)

'It's brilliant because you [potentially] have somebody on hand all the time, instead of feeling isolated at weekends or bank holidays, not getting an appointment with your GP [general practitioner], or nobody to talk to, because he doesn't have a heart failure nurse. We have nobody to talk to.' (UK, female, 60-69 years)

'If you've got input data, I'm sure if there were any difficulties, they [the potential doctor-at-home] would pick it up. Any abnormalities, they would pick them up. It would give assurance.' (Ireland, male, 70-79 years)

'If you have a device like this, and if you're putting in data on a daily basis, automatically it [the potential doctor-at-home] alerts you that there might be a problem.' (Ireland, male, 70-79 years)

Needs and Patients

expectations:

wish for support 'It's great to have somebody, you feel, you can ask questions on the spot. Sometimes if you have a question, you have to wait until you go to your doctor and you might get the answer, or you have to make the phone call, but with that I can [hypothetically] press a button and it comes up on a screen.' (Ireland, patient, female, 70-79 years)

'I've learned to write down what I want to ask when I go to a specialist. But the crazy thing is: I haven't been able to ask half of the questions.' (The Netherlands, male, participant of focus group, 60-69 years)

I've actually asked the doctors: What can I do? But not much came then. They help me with surgery and medication. I think they do that very well, so I rely on it. However, when it comes to what sport I can do, how should I eat... I think I can do an [envisioned] app that has learned that sport and nutrition are better for heart failure.' (Germany, male, 18-29 years)

'I think it's [potentially] quite good. It really is. You know, so, you'd probably feel a lot more, what would you say? Not confident, but at least you have somebody to turn over and say, so who understands what, where you're coming from.' (UK, female, 60-69 years)

'I would like to be more active, but I don't know whether it is good for my heart or not. So, if I want to do sports, l'd like to ask the [envisioned] application, I'm going to play tennis now, is that okay or isn't it.' (Germany, male, 60-69 years)

\section{Caregiver}

'I would find that very positive, if there was such a thing. It would give me at least a little bit more security as a relative. You just stand outside. You are not the patient. There's really not much you can do in an emergency.' (Germany, female, 50-59 years)

'Basically, in order to check whether everything is okay in everyday life, I definitely find it [the potential doctor-at-home] very useful.' (Germany, female, 50-59 years) 
Table 2 Continued

\begin{tabular}{ll}
\hline Theme & Example quotes \\
\hline $\begin{array}{l}\text { Preferences } \\
\text { regarding the }\end{array}$ & Patients \\
care process &
\end{tabular}

'I think possibly the only disadvantage I would say, and I've got to say this, is you're used to your own doctor. You're used to a real person.' (UK, male, 60-69 years)

'If a person is sitting with you, he or she can go along with your feelings. A machine doesn't do that. A machine is naturally flat. (...) It's a plus or a minus.' (The Netherlands, male, 70-79 years)

'Because you have a relationship. When I see her [the doctor], she knows what we were doing the last time and the time before. She may have to read her notes to remind her. (...) it's a face you know, a face you trust and a face that's shown my best interests are at heart in our conversations.' (UK, male, 60-69 years)

'I think it's important that the development is going to be that multiple specialists are reduced to actually one virtual person. So, I don't have to visit physically different specialists about my illnesses, every time. I can then get the information I need and the controls I need, from the new app that is to be developed for using at home.' (The Netherlands, patient, male, participant of focus group, 60-69 years)

'The personal touch is gone. That's the one thing that I would say about going digital with this kind of thing, because I think your health and conversations with the doctor are very personal.' (Ireland, male, 50-59 years)

'Patient: Because I prefer to go to a doctor and speak to a doctor personally.

Interviewer: Imagine that waiting times for a doctor's visit in the future would be even longer. Would that change your attitude to it?

Patient: No.' (Germany, female, 70-79 years)

\section{Perceived risk Patients}

'I wouldn't like it at all. I'd wait to see what was being done about it, if it's being corrected. You can understand a human being making a mistake, but when a machine makes a mistake, there's something wrong with the machine.' (Ireland, male, 60-69 years)

'You just have to accept it. Computers are computers and they can make mistakes. My Alexa goes off every now and again.' (Ireland, female, $70-79$ years)

'Interviewer: If it really was a mistake. Would you lose faith in it [the doctor-at-home]?

Patient: No. Anyone can make a mistake. A doctor can also make a mistake. No, I wouldn't lose the trust.' (The Netherlands, male, 60-69 years)

Trust Patients

'I would need to build up a trust in it [the envisioned doctor-at-home]. We start from zero.' (Ireland, male, 60-69 years)

'I assume she [the doctor-at-home to be build] was programmed by expert people in that field. Because of that, it not just pulling it out of thin air, it has been programmed so the advice would be good, and how you would tailor it.' (UK, caregiver, female, 60-69 years)

'If they decided to change medication or add an extra tablet, I'm sure that would be based on research that they would have on other patients with similar problems.' (Ireland, male, 70-79 years)

'What I need from her [the envisioned doctor-at-home] is that I can see the data on which its expertise is based. (...) This kind of information, basic information that ultimately gives the recommendation.' (The Netherlands, male, 60-69 years)

Continued 


\begin{tabular}{l} 
Table 2 Continued \\
\hline Theme \\
'Yesample quotes \\
from. In the end whether this advice, this instruction corresponds to what a doctor would tell me.' (Germany, male, 60-69 \\
years) \\
'But I mean, I don't think it's weird anymore when I put my grandson on my hand by Skype. I think that's perfectly normal. (...) \\
But these developments, getting used to the medical backup that is not provided by the doctor, is a period of getting used to.' \\
(The Netherlands, male, 60-69 years) \\
Caregiver \\
'I assume she [the doctor-at-home] was programmed by expert people in that field. Because of that, it not just pulling it out of \\
thin air, it has been programmed so the advice would be good, and how you would tailor it.' (UK, female, 60-69 years)
\end{tabular}

\section{Preferences regarding the care process}

Preferences of patients regarding healthcare delivery were dominated by the perceived benefits of the familiar patient-doctor relationship and the human aspects of care processes.

Many patients assumed that a doctor could react better to visual or non-verbal clues, such as body language and current emotional state. Patients described the relationship between doctors and patients as one that usually develops over time. This was important for some patients, since this commitment was associated with a good and individualised treatment.

Some patients saw the advantages of a potential doctorat-home for the care process. However, although many patients and informal caregivers recognised that this new technology will probably play a big role in future care processes and expressed a general openness towards a doctor-at-home, they still wanted regular visits to a doctor, even if waiting times should increase.

\section{Perceived risk}

Most patients talked about their fear that any mistake caused by the envisioned doctor-at-home could be potentially life threatening. Therefore, errors were often seen as major risk and a reason not to implement the advice, or even to stop using the system altogether. There was a clear distinction between the acceptance of the human (doctor) weakness to make mistakes compared with the possibility of errors made by a digital solution.

However, some patients were not that strict and were willing to give the future system a second chance or assumed that errors could be avoided by additional medical supervision, especially at the beginning of the usage. Additionally, some patients suggested a mechanism to report errors to ensure further improvement of the system.

\section{Trust}

Most participants emphasised that trust in the doctor-athome is a prerequisite for following any recommendations. Both groups expressed having more trust in the system from the beginning if they knew that it has been built by experts, such as HF specialists. They would trust the future doctor-at-home if it was validated, included the data of many patients with $\mathrm{HF}$ and/or was specifically recommended by their doctor. Many patients and informal caregivers expected that transparent decision-making by a future doctor-at-home would also positively influence their trust. Many participants thought that trust in the envisioned doctor-at-home comes with experience and time. Some patients and informal caregivers told us that it is just a matter of getting used to the new technology, comparing the application to a navigation system or a video chat.

\section{Summary of facilitators and barriers}

Based on these results we identified core aspects for the future users that could facilitate acceptance along with facets that should be considered and monitored within the development and implementation process (table 3 ).

\section{DISCUSSION}

The early involvement of patients and informal caregivers has provided us with a comprehensive understanding of potential facilitators and barriers regarding the acceptance of a doctor-at-home for patients with $\mathrm{HF}$ and their caregivers. Overall, patients and informal caregivers were very receptive towards the idea of using a doctor-at-home. They saw the potential main benefit of the system as reassurance whenever and wherever they need it.

'Uncertainty', caused by varied and uncontrollable symptoms, is a key component of the illness experience and negatively influences the health-related quality of life of patients with chronic diseases. ${ }^{29}$ While the general wish for reassurance is reflected in other studies, ${ }^{30} 31$ our participants also strongly expressed a need to get a health status update immediately. Real-time, personalised feedback may be helpful for motivating users. ${ }^{32}$ Hence, the immediate feedback could provide the desired safety while at the same time support adherence. Furthermore, HF is often accompanied by depression and anxiety. ${ }^{29}$ Anxiety, in particular, was a reoccurring theme throughout the interviews. A doctor-at-home could reduce anxiety, as previously shown. ${ }^{32}$ Besides the psychological benefits, our participants acknowledged the envisioned opportunities of data processing and AI. Many of them 
Table 3 Summary of the determinants influencing the acceptance of a doctor-at-home

\begin{tabular}{|c|c|}
\hline $\begin{array}{l}\text { Benefits of a doctor-at-home for } \\
\text { patients and informal caregivers. }\end{array}$ & $\begin{array}{l}\text { Reassurance whenever and wherever needed. } \\
\text { Support in managing the daily routine with the disease. } \\
\text { Monitoring of the health status } 24 / 7 \text {, including immediate feedback. } \\
\text { Early detection of a worsening health status. }\end{array}$ \\
\hline $\begin{array}{l}\text { Facilitate a change in the familiar } \\
\text { care process of the patients. }\end{array}$ & $\begin{array}{l}\text { Assumption of the patients that human factors are important for quality of care. } \\
\text { General openness towards the integration of a doctor-at-home in the care processes. } \\
\text { Preference to have both-physical doctor and doctor-at-home. }\end{array}$ \\
\hline $\begin{array}{l}\text { Consider the perceived risk of } \\
\text { mistakes. }\end{array}$ & $\begin{array}{l}\text { Patients' perception and acceptance of mistakes differ between doctors and a } \\
\text { doctor-at-home. } \\
\text { Solution could be a supervision of decisions made by doctor-at-home, especially in } \\
\text { the early stages, and a reporting function for mistakes. }\end{array}$ \\
\hline
\end{tabular}

HF, heart failure.

expected that a more personalised and preventive treatment may be possible with a doctor-at-home. The findings that frequent telemonitoring could positively influence patients' health, ${ }^{33-35}$ the enormous potential of big data analytics in healthcare ${ }^{36-38}$ and the possibility to spot adverse drug events and interactions ${ }^{39}$ are also reflected in literature. Our interviews were conducted before the COVID-19 crisis. However, the pandemic was accompanied by a reduction of visits to the general practitioner and specialist by almost half. ${ }^{40}$ Therefore, the need for a digital solution that provides safe, accessible and personalised healthcare ${ }^{41}$ has grown even further since our study was conducted. ${ }^{42}$ Another possible benefit was the ability of a doctor-at-home to make patients feel listened to and cared for. By using a system such as the doctor-at-home they expected to have the feeling that someone-even if it was a digital application-is always in the background looking after them. ${ }^{43}{ }^{44}$ Digital technologies have been shown to react individually to the needs of patients and directly support self-care, reduce doctors' office visits, prevent emergencies or hospitalisations ${ }^{4546}$ and contribute to an improved quality of life. ${ }^{47}$ Finally, the prospective digital support could be of great benefit for the informal caregivers by providing advice regarding the health of their loved ones, similar to experiences reported in other studies. ${ }^{48}$

However, the future implementation of a doctor-at-home will involve a change in behaviour, especially regarding familiar care processes. One particular concern of our participants, also discussed within literature, was an impact on the patient-doctor relationship. ${ }^{50}$ Aligned with previous research, patients related face-to-face interactions with trust, sympathy and better communication. ${ }^{51}$ Nevertheless, our participants stated that the importance of the personal patient-doctor relationship is much influenced by familiarisation and may change over time.

Our findings emphasise the need for more research in regard to how mistakes are perceived by patients and informal caregivers. Research has established the inclination for users to blame new technologies for errors because of very high expectations. ${ }^{52}$ Our results support these findings.

Finally, our participants highlighted the importance of trust as a belief that the envisioned doctor-at-home will deliver what was promised. Establishing trust is particularly important within healthcare settings. ${ }^{53-55}$ Satisfaction with treatment and adherence is higher if the patient trusts the doctor. ${ }^{567}$ Our participants mentioned concrete prospects to establish trust. They felt that over time and after gaining experience of responsive, roundthe-clock support, the acceptance and potential use of a doctor-at-home could increase.

\section{Strengths and limitations of the study}

Our study is strengthened by the integration of the patients and informal caregivers from four European countries as future users of the new technology. Differences of the patient characteristics between countries may 
have influenced the results. However, the aim of this study was to provide an overview of determinants that influence the potential acceptance of patients and their informal caregivers regarding a patient-oriented digital decisionmaking solution system independent of country or healthcare system characteristics. Although we attempted to include a well-balanced sample of participants, some limitations apply. Due to a limited time frame for data collection, we included those patients in the interviews who expressed their willingness and availability. This led to an imbalance in gender of the patients that does not represent the healthcare reality. ${ }^{58}$ This discrepancy also caused an unequal gender distribution among informal caregivers. Furthermore, our patients were slightly younger than the average $\mathrm{HF}$ population ${ }^{59}$ and the majority of them had mild symptoms (NYHA I and II). However, we expect that the desire for reassurance and support increases with age and the severity of symptoms and the disease. Also, there is a lack of racial, and limited ethnic and educational diversity. It is therefore possible that we have missed some specific needs. Although a wide range of experiences were included, the interview study relied on voluntary participation, making a sampling bias possible. ${ }^{60}$ Finally, potential interviewer bias cannot be completely excluded. However, all researchers used a uniformed interview guide, were trained and supervised by one experienced person and reported directly back to the trainer (AP) after each interview, which determined a high interview fidelity.

\section{CONCLUSION}

To our knowledge, this is the first study to report the perspectives of patients and their informal caregivers regarding potential facilitators and barriers regarding the acceptance of an interactive decision-making system for patients. Our findings demonstrate that patients with $\mathrm{HF}$ and their informal caregivers see the potential of a doctor-at-home to offer high quality of care in the future. They expect the envisioned system to support their individual disease management regardless of time, location or availability of healthcare providers and are willing to incorporate it into their care processes. Given the familiarity and security with current face-to-face visits with doctors, they are reluctant to lose this personal contact. However, they can imagine a change, but highlight that this may need time. In the face of the COVID-19 crisis, the time to get used to the change might be accelerated. To sum up, the in-depth understanding gained from the perceptions and expectations of patients and caregivers will help optimise the development of such new systems and subsequently reduce the time to achieve the required paradigm change.

\footnotetext{
Author affiliations

${ }^{1}$ Deutsche Stiftung für chronisch Kranke, Berlin, Germany

${ }^{2}$ Cardiology Department, Laurentius Hospital, Roermond, The Netherlands

${ }^{3}$ Integrated Care Academy, University of Suffolk, Ipswich, UK

${ }^{4}$ School of Nursing and Midwifery, Queen's University, Belfast, UK
}

${ }^{5}$ Belfast Health and Social Care Trust, Belfast, UK

${ }^{6}$ Department of Cardiology, University Hospital Aachen, Aachen, Germany

${ }^{7}$ Thomas More University of Applied Sciences, Geel, Belgium

${ }^{8}$ Catherine McAuley Education and Research Centre, University College of Dublin, Dublin, Ireland

${ }^{9}$ Sananet Care, AL Sittard, The Netherlands

${ }^{10}$ Cardiology Department, Maastricht University Medical Centre+, Maastricht, The Netherlands

Acknowledgements This paper was written on behalf of the PAtient Self-care uSing eHealth In chrONic Heart Failure (PASSION-HF) consortium.

Contributors BZS, AP and CE had full access to all data and take responsibility for the integrity of the data and the accuracy of the data analysis. All three contributed equally to this work. Concept and design: BZS, AP, CE, HPBLR, TH, LdM, TMH. Conducting the interviews: AP, CE, LH, JB, KAS, EFdL, LJD, DF, CFS, DRT. Quantitative and qualitative analyses: AP, BZS, CE. Interpretation of data: BZS, AP, CE, HPBLR, CFS, MB, JB. Drafting of the manuscript: AP, BZS, CE. Critical revision of the manuscript for important intellectual content and final approval: BZS, AP, CE, HPBLR, TMH, CFS, LH, DRT, JB, KAS, LdM, MB, EFdL, TH, LJD, DF. Supervision: HPBLR, TMH.

Funding This project, PAtient Self-care uSing eHealth In chrONic Heart Failure (PASSION-HF), was supported by INTERREG-NWE VB (grant number NWE 702).

Competing interests None declared.

Patient consent for publication Not required.

Ethics approval The protocol for this study was approved by Queen's University Belfast, St Vincent's Healthcare Group Dublin, Maastricht Universitair Medisch Centrum, Uniklinik RWTH Aachen.

Provenance and peer review Not commissioned; externally peer reviewed.

Data availability statement Data sharing not applicable as no data sets generated and/or analysed for this study. Data are available upon reasonable request. Code scheme from ATLAS.ti software.

Supplemental material This content has been supplied by the author(s). It has not been vetted by BMJ Publishing Group Limited (BMJ) and may not have been peer-reviewed. Any opinions or recommendations discussed are solely those of the author(s) and are not endorsed by BMJ. BMJ disclaims all liability and responsibility arising from any reliance placed on the content. Where the content includes any translated material, BMJ does not warrant the accuracy and reliability of the translations (including but not limited to local regulations, clinical guidelines, terminology, drug names and drug dosages), and is not responsible for any error and/or omissions arising from translation and adaptation or otherwise.

Open access This is an open access article distributed in accordance with the Creative Commons Attribution Non Commercial (CC BY-NC 4.0) license, which permits others to distribute, remix, adapt, build upon this work non-commercially, and license their derivative works on different terms, provided the original work is properly cited, appropriate credit is given, any changes made indicated, and the use is non-commercial. See: http://creativecommons.org/licenses/by-nc/4.0/.

ORCID iDs

Alexander Palant http://orcid.org/0000-0003-2371-6928

Chantal F Ski http://orcid.org/0000-0003-1324-2933

Lieven de Maesschalck http://orcid.org/0000-0002-4486-0497

\section{REFERENCES}

1 Ziaeian B, Fonarow GC. Epidemiology and aetiology of heart failure. Nat Rev Cardiol 2016;13:368-78.

2 Lund LH, Savarese G. Global public health burden of heart failure. Cardiac Fail Rev 2017;03.

3 Christ M, Störk S, Dörr M, et al. Heart failure epidemiology 20002013: insights from the German federal health monitoring system. Eur J Heart Fail 2016;18:1009-18.

4 Vanagas G, Umbrasiene J, Slapikas R, et al. Effectiveness of telemedicine and distance learning applications for patients with chronic heart failure. A protocol for prospective parallel group non-randomised open label study. BMJ Open 2012;2. doi:10.1136/ bmjopen-2012-001346. [Epub ahead of print: 2509 2012].

5 Díaz-Toro F, Verdejo HE, Castro PF. Socioeconomic inequalities in heart failure. Heart Fail Clin 2015;11:507-13. 
6 Braunschweig F, Cowie MR, Auricchio A. What are the costs of heart failure? Europace 2011;13:ii13-17.

7 Aldred H, Gott M, Gariballa S. Advanced heart failure: impact on older patients and informal carers. J Adv Nurs 2005;49:116-24.

8 Blank WA. [A Successful Strategy against the Expected Shortage of Physicians in Rural Areas]. Gesundheitswesen 2021;83:86-94.

9 Latifi R. The Modern Hospital - Patients Centered, Disease Based, Research Oriented, Technology Driven. Valhalla, NY: Springer, 2019.

10 Cajita MI, Hodgson NA, Budhathoki C, et al. Intention to use mHealth in older adults with heart failure. J Cardiovasc Nurs 2017;32:E1-7.

11 Nsoesie EO. Evaluating artificial intelligence applications in clinical settings. JAMA Netw Open 2018;1:e182658.

12 Koehler F, Koehler K, Deckwart O, et al. Efficacy of telemedical interventional management in patients with heart failure (TIM-HF2): a randomised, controlled, parallel-group, unmasked trial. Lancet 2018;392:1047-57.

13 Foster M. A mobile application for patients with heart failure: Theoryand evidence-based design and testing. Comput Inform Nurs 2018;36:540-9.

14 Choi D-J, Park JJ, Ali T, et al. Artificial intelligence for the diagnosis of heart failure. NPJ Digit Med 2020;3:54

15 Richardson LP, Zhou C, Gersh E, et al. Effect of electronic screening with personalized feedback on adolescent health risk behaviors in a primary care setting: a randomized clinical trial. JAMA Netw Open 2019;2:e193581.

16 Barrett M, Boyne J, Brandts J, et al. Artificial intelligence supported patient self-care in chronic heart failure: a paradigm shift from reactive to predictive, preventive and personalised care. Epma $J$ 2019:10:445-64.

17 Kujala1 S. Effective user involvement in product development by improving the analysis of user needs. Behav Inf Technol 2008;27:457-73.

18 Carter N, Bryant-Lukosius D, DiCenso A, et al. The use of triangulation in qualitative research. Oncol Nurs Forum 2014;41:545-7.

19 Thurmond VA. The point of triangulation. J Nurs Scholarsh 2001;33:253-8

20 Venkatesh V, Thong JYL, Xu X. Consumer acceptance and use of information technology: extending the unified theory of acceptance and use of technology. Behavioral Market eJournal 2012.

21 Slade EL, Dwivedi YK, Piercy NC, et al. Modeling consumers' adoption intentions of remote mobile payments in the United Kingdom: Extending UTAUT with innovativeness, risk, and trust. Psychol Mark 2015;32:860-73.

22 Sun H, Zhang P. The role of Moderating factors in user technology acceptance. Int J Hum Comput Stud 2006;64:53-78.

23 Cocosila M, Archer N. Practitioner pre-adoption perceptions of electronic medical record systems. Behav Inf Technol 2017;36:827-38.

24 Gefen D, Karahanna E, Straub DW. Trust and TAM in online Shopping: an integrated model. MIS Quarterly 2003;27:51-90.

25 White PD, Myers MM. The classification of cardiac diagnosis. JAMA 1921;77:1414-5.

26 Hellodocpal. Sensely virtual health assistant "Molly". YouTube, 2017. Available: https://www.youtube.com/watch?v=AU1nGpOmZpQ\&ab_ channel=hellodocpal [Accessed 15 Mar 2021].

27 Mayring P. Qualitative content analysis: theoretical foundation, basic procedures and software solution. Klagenfurt. In: Qualitative Inhaltsanalyse: Grundlagen und Techniken. Weinheim and Basel: Beltz, 2015. https://nbn-resolving.org/urn:nbn:de:0168-ssoar-395173

28 Downe-Wamboldt B. Content analysis: method, applications, and issues. Health Care Women Int 1992;13:313-21.

29 Chen T-Y, Kao C-W, Cheng S-M, et al. Uncertainty and depressive symptoms as mediators of quality of life in patients with heart failure. PLoS One 2018;13:e0205953.

30 Higgins JP. Smartphone applications for patients' health and fitness. Am J Med 2016:129:11-19.

31 Kerr DA, Harray AJ, Pollard CM, et al. The connecting health and technology study: a 6-month randomized controlled trial to improve nutrition behaviours using a mobile food record and text messaging support in young adults. Int J Behav Nutr Phys Act 2016;13:52.

32 Lee M, Lee H, Kim Y, et al. Mobile app-based health promotion programs: a systematic review of the literature. Int $J$ Environ Res Public Health 2018;15:2838

33 Walker RC, Tong A, Howard K, et al. Patient expectations and experiences of remote monitoring for chronic diseases: systematic review and thematic synthesis of qualitative studies. Int J Med Inform 2019;124:78-85.
34 Inglis SC, Clark RA, Dierckx R. Structured telephone support or non-invasive telemonitoring for patients with heart failure. Cochrane Database Syst Rev 2015;10:Cd007228.

35 Dendale P, De Keulenaer G, Troisfontaines P, et al. Effect of a telemonitoring-facilitated collaboration between general practitioner and heart failure clinic on mortality and rehospitalization rates in severe heart failure: the TEMA-HF 1 (TElemonitoring in the management of heart failure) study. Eur $\mathrm{J}$ Heart Fail 2012;14:333-40.

36 Mehta N, Pandit A. Concurrence of big data analytics and healthcare: a systematic review. Int J Med Inform 2018;114:57-65.

37 Martin-Sanchez F, Verspoor K. Big data in medicine is driving big changes. Yearb Med Inform 2014;9:14-20.

38 Goldstein BA, Carlson D, Bhavsar NA. Subject matter knowledge in the age of big data and machine learning. JAMA Netw Open 2018;1:e181568.

39 Ventola CL. Big data and pharmacovigilance: data mining for adverse drug events and interactions. P T 2018;43:340-51.

40 De Filippo O, D'Ascenzo F, Angelini F, et al. Reduced rate of hospital admissions for ACS during Covid-19 outbreak in northern Italy. $N$ Engl J Med 2020;383:88-9.

41 Ski CF, Zippel-Schultz B, De Maesschalck L, et al. COVID-19 shapes the future for management of patients with chronic cardiac conditions. Digit Health 2021;7:205520762199171.

42 Golinelli D, Boetto E, Carullo G, et al. Adoption of digital technologies in health care during the COVID-19 pandemic: systematic review of early scientific literature. J Med Internet Res 2020;22:e22280.

43 Fairbrother P, Ure J, Hanley J, et al. Telemonitoring for chronic heart failure: the views of patients and healthcare professionals - a qualitative study. J Clin Nurs 2014;23:132-44.

44 Mortara A, Oliva F, Di Lenarda A. [Current perspectives in telemonitoring and devices in chronic heart failure patients: lights and shadows]. G Ital Cardiol 2010;11:33S-7.

45 Safi S, Thiessen T, Schmailzl KJ. Acceptance and resistance of new digital technologies in medicine: qualitative study. JMIR Res Protoc 2018;7:e11072.

46 Spoelman WA, Bonten TN, de Waal MWM, et al. Effect of an evidence-based website on healthcare usage: an interrupted timeseries study. BMJ Open 2016;6:e013166.

47 Toback M, Clark N. Strategies to improve self-management in heart failure patients. Contemp Nurse 2017;53:105-20

48 Golics CJ, Basra MKA, Finlay AY, et al. The impact of disease on family members: a critical aspect of medical care. J R Soc Med 2013;106:399-407.

49 Donovan-Kicken E, Bute JJ. Uncertainty of social network members in the case of communication-debilitating illness or injury. Qual Health Res 2008:18:5-18.

50 McDougall RJ. Computer knows best? The need for value-flexibility in medical Al. J Med Ethics 2019;45:156-60.

51 Vaportzis E, Clausen MG, Gow AJ. Older adults perceptions of technology and barriers to interacting with tablet computers: a focus group study. Front Psychol 2017;8:1687.

52 Madhavan P, Wiegmann DA. Effects of information source, pedigree, and reliability on operator interaction with decision support systems. Hum Factors 2007;49:773-85

53 Hams SP. Concept analysis of trust: a coronary care perspective. Intensive Crit Care Nurs 1997;13:351-6.

54 Duquenoy P, Mekawie NM, Patients SM. trust and ethics in information privacy in ehealth. In: George C, ed. eHealth: legal, ethical and governance challenges. Berlin: Springer, 2012: 275-95.

55 Kanter GP, Carpenter D, Lehmann LS, et al. US nationwide disclosure of industry payments and public trust in physicians. JAMA Netw Open 2019;2:e191947.

56 Griese N, Schorr SG, Schulz M. [Care of patients with heart failure] Pharm Unserer Zeit 2012;41:343-9.

57 Forsyth P, Richardson J, Lowrie R. Patient-reported barriers to medication adherence in heart failure in Scotland. Int $\mathrm{J}$ Pharm Pract 2019;27:443-50.

58 Adams KF, Fonarow GC, Emerman CL, et al. Characteristics and outcomes of patients hospitalized for heart failure in the United States: rationale, design, and preliminary observations from the first 100,000 cases in the acute decompensated heart failure national registry (adhere). Am Heart J 2005;149:209-16.

59 Lloyd-Jones DM, Larson MG, Leip EP, et al. Lifetime risk for developing congestive heart failure: the Framingham heart study. Circulation 2002;106:3068-72.

60 Robinson OC. Sampling in Interview-Based qualitative research: a theoretical and practical guide. Qual Res Psychol 2014;11:25-41. 